\title{
Hepatitis B Virus Seroprevalence and Serology Patterns in a Cohort of HIV Positive Individuals from Harare, Zimbabwe
}

\author{
Mayibongwe Louis Mzingwane ${ }^{1,2}$ and Tafadzwa Mamvura ${ }^{2}$ \\ ${ }^{1}$ Division of Basic Medical Sciences, National University of Science and Technology, P.O. Box AC939, Ascot, Bulawayo, Zimbabwe \\ ${ }^{2}$ Department of Medical Microbiology, University of Zimbabwe College of Health Sciences, Mazowe Street, \\ P.O. Box A178, Avondale, Harare, Zimbabwe
}

Correspondence should be addressed to Mayibongwe Louis Mzingwane; mayibongwe.mzingwane@nust.ac.zw

Received 19 September 2014; Accepted 4 November 2014; Published 27 November 2014

Academic Editor: Massimo Ciccozzi

Copyright (C) 2014 M. L. Mzingwane and T. Mamvura. This is an open access article distributed under the Creative Commons Attribution License, which permits unrestricted use, distribution, and reproduction in any medium, provided the original work is properly cited.

\begin{abstract}
Zimbabwe is highly endemic for hepatitis B virus (HBV) and also has high human immunodeficiency virus (HIV) prevalence rates which may result in HIV/HBV coinfection, and as HIV/HBV coinfection may affect the classical HBV serology patterns and cause interpretation challenges, we assessed the seroprevalence of HBV in HIV positive patients and determined their serology profiles. This was a cross-sectional study on 957 HIV positive specimens from treatment naive patients. HBV serology tests were done using enzyme immunoassays for the detection of HBV markers in human serum or plasma. Hepatitis B surface antigen (HBsAg) prevalence was $17.1 \%$ (males $19.0 \%$, females $15.8 \%$ ). Previous and/or current HBV exposure was evident in $59.8 \%$ of the patients and hepatitis B e antigen markers were present in 103 (10.8\%) specimens. There was high prevalence of unusual HBV patterns with $14.1 \%$ of total specimens showing an anti-HBc alone profile and an additional $4.3 \% \mathrm{HBsAg}$ positive specimens that were anti-HBc negative.
\end{abstract}

\section{Introduction}

Hepatitis B virus (HBV) can cause both acute and chronic disease and is the leading cause of viral hepatitis worldwide [1]. An estimated two billion people have been infected with HBV and more than 350 million have chronic HBV liver infections resulting in about 600000 deaths every year [2]. It was previously reported that Zimbabwe has an overall HBV surface antigen (HBsAg) seroprevalence rate of $15.4 \%$ in the general population [3] and is classified as a high HBV endemic area. Zimbabwe also has high HIV prevalence rates of around $15 \%$ in the general population [4], but there is little or no data on HBV and HIV coinfection. The prevalence of HIV infected Zimbabweans carrying HBV serological markers is not known. Although some studies in sub-Saharan Africa have shown no major increase of HBV prevalence in HIV patients [5] other studies have reported higher HBV prevalence in HIV patients [6, 7]. This piece of information will be important as the clinical impact of HBV infection in HIV positive patients has progressively grown since the introduction of highly active antiretroviral therapy (HAART) given the increase in survival rates experienced by these patients who now experience the effect of other chronic infections such as HBV. Chronic HBV infection is defined as persistent detection of HBV surface antigen (HBsAg) for more than 6 months $[8,9]$. HIV/HBV coinfections may have negative implications on chronic HBV patients including increased rates of chronic HBsAg positivity, high HBV DNA levels, and lower rates of anti-hepatitis $B$ virus e antigen (anti$\mathrm{HBe}$ ) seroconversion [10]. HIV/HBV coinfected patients also have increased risk of progression to end stage liver disease and hepatocellular carcinoma [11].

Although development of HBV drug resistance in HBV positive patients who are put on tenofovir (TDF) based highly active antiretroviral therapy (HAART) has been shown to be unlikely [12-14] since antiretroviral therapy (ART) drugs aimed at HIV such as TDF and lamivudine (3TC) are also active against HBV, most of these studies have been conducted in countries with low HBV endemicity which occurs primarily in adulthood. However the management of 
HBV/HIV coinfections and development of HBV or HIV resistance for patients on HAART in high HBV and HIV endemic areas has not been well studied and may present a challenge [15] especially in the absence of guidelines for the treatment of HBV/HIV coinfections. In high HBV endemic countries transmission occurs early in childhood [15]; thus HBV is already established prior to HIV infection and HAART initiation and most patients initiating HAART in developing countries and resource-limited settings are already at an advanced disease stage with low CD4 counts and high viral loads. In addition, coinfection of HBV and HIV may make the reporting of HBV infection stage difficult especially in highly immune-suppressed patients as unusual HBV marker combinations such as hepatitis B virus core antibody (anti-HBc) alone, loss of or failure to detect anti-HBc, and reappearance of active HBV serology markers resulting in interpretation challenges and complication of management $[5,6,16,17]$. It is therefore important to characterize HIV/HBV coinfections for developing countries to better understand the scope of the disease and guide health policy in prioritizing and optimizing treatment needs for poor resource settings. We determined the prevalence of $\mathrm{HBV}$ serology markers in a cohort of 957 HIV positive individuals from Zimbabwe and interpreted their HBV serology profiles.

\section{Methods}

This was a cross-sectional study in HIV positive patients initiating tenofovir (TDF) and lamivudine (3TC) combination therapy as part of HAART in specimens collected between the years 2003 and 2009. Participants received 3TC and zidovudine (AZT) as Combivir together with TDF. We investigated the baseline HBV serology patterns and the prevalence of $\mathrm{HBV}$ coinfection in this cohort.

2.1. Specimens. Clinical specimens were obtained from archived baseline serum specimens from HIV-1 positive patients initiating TDF/3TC combination therapy as part of HAART. The specimens were stored at $-80^{\circ} \mathrm{C}$. Demographic data on sex and age of participants at baseline was obtained from the patients records. Baseline specimens from 957 patients were investigated. All patients were treatment naive and had advanced acquired immunodeficiency syndrome (AIDS) with a CD 4 count of less than 200 cells/ $\mu \mathrm{L}$.

2.2. Serology Assays. HBV serology tests were done using the Abbott Murex kits (Murex Biotech Limited, UK) and the DiaSorin kits (DiaSorin S.p.A., Italy) per the kit manufacturer's instructions using a set test plan (Figure 1).

The Abbott Murex HBsAg test kit was used for the HBsAg screening test on all specimens. All specimens were tested twice for HBsAg using the screening test. HBsAg positive specimens were then further tested with the Abbott Murex HBsAg confirmatory test kit. Only specimens confirmed to be positive with the Abbott Murex HBsAg confirmatory test kit were recorded as HBsAg positive. All specimens were also tested for the anti-HBc marker using the Abbott Murex anti$\mathrm{HBc}$ (total) test kit. Specimens found to be HBsAg negative

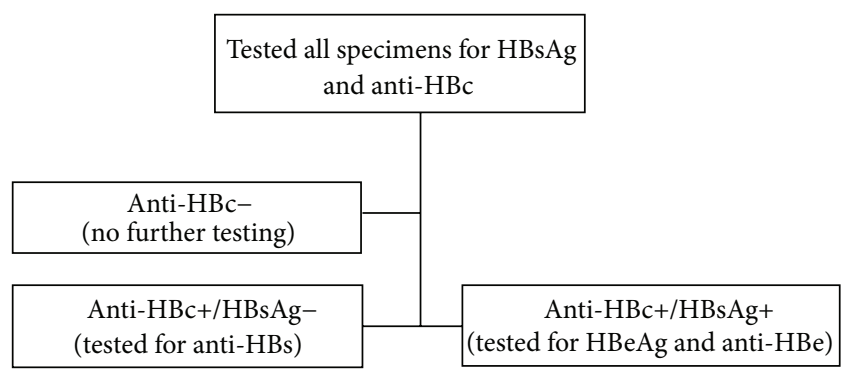

FIGURE 1: HBV serology test plan. All specimens were tested for $\mathrm{HBsAg}$ and anti-HBc (total) with further testing for anti-HBs or $\mathrm{HBeAg}$ and anti-HBe depending on the $\mathrm{HBsAg}$ and anti-HBc result combination.

but anti- $\mathrm{HBc}$ (total) reactive were then tested for the presence of anti-HBs using the Murex anti-HBs test kit. Active HBV was also determined by testing for the presence of HBeAg and anti-HBe markers using the DiaSorin ETI-EBK PLUS and ETI-AB-EBK PLUS test kits for HBeAg and anti-HBe tests, respectively. All the tests used are enzyme immunoassays for the detection of HBV markers in human serum or plasma.

2.3. Statistical Analysis. Demographic descriptive statistics was used to analyse the results. The $Z$-test for difference in proportions was used to compare the prevalence from different groups.

\section{Results}

3.1. Demographics and Specimens Tested. Specimens from a total of 957 individuals were tested with the majority of them being females (57.7\%). The majority of participants were in the $30-39$ age group with $46.7 \%$ of male participants, $51.8 \%$ of female participants, and $49.6 \%$ of all participants overall. The 50-year- and-over age group had the lowest number of participants $(6.8 \%)$ but in terms of gender distribution the lowest number of males was in the 18-29 age group (7.9\%) while the 50-year- and-over age group had the lowest number of females (5.1\%). The detailed distribution of participants by gender and age is shown in Supplementary Figure S1(A) (see the Supplementary Material available online at http://dx.doi.org/10.1155/2014/691953).

3.2. HBV Serology Results and Profiles. 164 subjects out of 957 were confirmed to be $\mathrm{HBsAg}$ positive giving $17.1 \% \mathrm{HBsAg}$ seroprevalence in the cohort. The difference in the overall proportions of males and females infected with HBV (males $19.0 \%$, females $15.8 \% ; P=0.18684$ ) and across the different age groups in this population was not significant except for the 18-29-year age group (males $31.25 \%$, females $13.54 \%$; $P=$ 0.02382 ). The HBsAg prevalence was consistent across the age groups $(17.1 \%-18 \%)$ except the $>50$-year age category which had the lowest prevalence of $10.8 \%$. The detailed HBsAg seroprevalence in different age groups and the distribution by gender are shown in Figure S1(B). There were 531 (55.5\%) specimens that were positive for the anti- $\mathrm{HBc}$ marker. A total of 572 specimens were positive for either anti-HBc or 
TABLE 1: HBV serology.

\begin{tabular}{|c|c|}
\hline & HIV cohort $(n=957)$ \\
\hline Males & $405(42.3 \%)$ \\
\hline Females & $552(57.7 \%)$ \\
\hline \multicolumn{2}{|l|}{ HBsAg seropositivity } \\
\hline Overall & $164(17.1 \%)$ \\
\hline Males & $77(19.0 \%)^{\#}$ \\
\hline Females & $87(15.8 \%)^{\#}$ \\
\hline \multicolumn{2}{|l|}{ HBV exposure } \\
\hline Anti-HBc+ & $531(55.5 \%)$ \\
\hline${ }^{*} \mathrm{HBsAg}+/$ anti-HBc- & $41(4.3 \%)$ \\
\hline Total HBV exposure & $572(59.8 \%)$ \\
\hline \multicolumn{2}{|l|}{ HBV profiles (infection stage) } \\
\hline Anti-HBc+/HBsAg-/anti-HBs+ (resolved) & $232(24.2 \%)$ \\
\hline Anti-HBc+/HBsAg+/HBeAg+/anti-HBe- (active) & $45(4.7 \%)$ \\
\hline Anti-HBc+/HBsAg+/HBeAg-/anti-HBe+ (active resolving) & $58(6.1 \%)$ \\
\hline Anti-HBc+/HBsAg+/HBeAg-/anti-HBe- (acute resolving or chronic inactive carrier) & $20(2.1 \%)$ \\
\hline${ }^{*}$ Anti-HBc alone & $135(14.1 \%)$ \\
\hline${ }^{\dagger} \mathrm{HBs} \mathrm{Ag}+/ \mathrm{anti}-\mathrm{HBc}-$ & $41(4.3 \%)$ \\
\hline${ }^{\ddagger}$ Anti-HBc+/HBsAg- (not classified, no anti-HBs result) & 41 \\
\hline Anti-HBc-/HBsAg- (HBV negative) & $385(40.2 \%)$ \\
\hline \multicolumn{2}{|l|}{$\mathrm{HCV}$ infection } \\
\hline HCV infected patients & $19(2.0 \%)$ \\
\hline HIV and HCV only & $9(0.9 \%)$ \\
\hline \multicolumn{2}{|l|}{$\mathrm{HCV}$ in $\mathrm{HBV}$ positive patients } \\
\hline Total HCV infections & $10(1.0 \%)$ \\
\hline $\mathrm{HCV} / \mathrm{HBsAg}+/ \mathrm{HBeAg}+(\mathrm{HCV}$ with active $\mathrm{HBV})$ & 2 \\
\hline $\mathrm{HCV} /$ anti-HBc alone (HCV with possible occult HBV) & 2 \\
\hline $\mathrm{HCV} /$ anti-HBc+/anti-HBs+ (HCV with resolved HBV) & 6 \\
\hline
\end{tabular}

${ }^{*, \dagger}$ Problematic profiles that need HBV DNA data for classification. ${ }^{*}$ Insufficient volume for anti-HBs test.

${ }^{\#} P=0.18684$

HBsAg or both giving a seroprevalence rate of $59.8 \%$ for these HBV primary markers. There were 232 (24.2\%) specimens with detectable anti-hepatitis B virus surface antigen (anti$\mathrm{HBs}$ ) and these were classified as having resolved HBV. The anti-HBs test was not done on 41 specimens because of insufficient volume. The hepatitis B virus e antigen ( $\mathrm{HBeAg}$ ) was detected in 45 (4.7\%) specimens indicating active HBV and $58(6.1 \%)$ specimens were anti-HBe positive and were classified as active resolving. There were 20 (2.1\%) negative specimens for $\mathrm{HBe}$ markers although being positive for both anti-HBc and HBsAg and these could be acute resolving cases or chronic inactive carriers.

\section{Discussion}

This was a study looking at the prevalence of hepatitis B in a cohort of HIV infected patients from Harare, Zimbabwe. We tested for the different antigens and antibodies that determine the hepatitis status. All specimens were tested for the HBsAg and anti-HBc primary markers with further testing for anti$\mathrm{HBs}$ and $\mathrm{HBe}$ markers in anti-HBc positive specimens. As expected high HBsAg prevalence of $17.1 \%$ was obtained in this cohort of HIV positive individuals given that Zimbabwe is a high HBV endemic area. The $17.1 \%$ seroprevalence is within the HBsAg positivity prevalence in HIV infected individuals range of $9 \%-100 \%$ found in other parts of Africa including sub-Saharan Africa $[6,18-21]$. The HBsAg seroprevalence obtained is equivalent to the HBV prevalence in the Zimbabwe general population during the pre-HBV vaccination era [3]. Figures in the general population of Zimbabwe are likely to have gone down especially in the younger generation as has been the trend worldwide because of HBV vaccination [22]. In Zimbabwe HBV vaccination was introduced into the expanded immunization program in 1994 [23].

The testing plan produced seven sets of serology marker profiles (Table 1). The possible stage of $\mathrm{HBV}$ infection for individuals in each of the exhibited profiles was determined but some unusual profiles were obtained which may be linked to HIV interference with normal HBV patterns. We had 135 specimens (14.1\%) exhibiting an isolated anti-HBc profile and these individuals may have occult HBV (HBV DNA in HBsAg negative individuals). Other studies have recorded $14 \%-17 \%$ of HIV positive individuals to have this serological profile [24-27], being more prevalent in immune-suppressed individuals with low CD4+ cell counts of less than 100 cells/ $\mu \mathrm{L}[6$, 14]. This may account for the high prevalence of this profile in our cohort as all our patients were highly immune-suppressed with $\mathrm{CD}+$ counts of less than 200 cells/ $\mu \mathrm{L}$. Underlying HCV 
coinfection has also been shown to be a risk factor for isolated anti-HBc [25-27]; however in our study only 2 out of 19 (10.5\%) HCV positive patients had isolated anti-HBc. The overall HCV prevalence was $2 \%$ in this population and this figure is consistent with $\mathrm{HCV}$ prevalence figures that have been recorded in the region [18]. Data on HIV/HCV coinfection is limited in Zimbabwe but one study recorded a prevalence of $0.8 \%$ [28] supporting the heterosexual nature of HIV and HBV transmission in Zimbabwe.

We also had an unusual profile of $4.3 \%$ specimens that were $\mathrm{HBsAg}$ positive but anti-HBc negative. Normally anti$\mathrm{HBc}$ is always detectable at the onset of disease or in chronic infections of immune competent individuals but may be lost in cases of severe immunodeficiency as in our patients [2931]. One study retested specimens that had been found to be anti- $\mathrm{HBc}$ negative when tested with an enzyme immunoassay and managed to detect anti-HBc in $25 \%$ of the specimens using a more sensitive assay [17]. A more anti-HBc sensitive test could have been used as a confirmatory test but two different tests were used for HBsAg detection in our cohort and we do not doubt their HBsAg positivity. In addition to immune suppression perinatal infection has been identified as a possible risk factor for undetectable anti-HBc [17]. Our cases could also be of very early disease stage as normally anti$\mathrm{HBc}$ should remain detectable instead of HBsAg in resolved HBV cases.

Although detailed HBV serology was done in this study an important limitation is that the study was conducted with a selected population which means that the prevalence of HBV in this cohort cannot be extrapolated to the general population of Zimbabwe. There is need to investigate the current prevalence of $\mathrm{HBV}$ in the general population as it is likely to have changed in the past 19 years because of HBV vaccination. Another limitation is that HBV DNA, an important HBV marker, could not be tested at this stage which could have given more information in interpreting problematic profiles such as the anti-HBc alone profile. HBV DNA testing would help in proper diagnosis of HBV in HIV positive patients but is currently not routinely used for HBV diagnosis in Zimbabwe. In conclusion, there was high prevalence of HBV coinfection in HIV infected individuals in this cohort (17.1\% HBsAg, 55.4\% anti-HBc, and 59.85\% HBsAg and/or anti-HBc seroprevalence) indicating high HBV prevalence in Zimbabwean HIV positive patients. These results underline the extent of HIV/HBV coinfection and will be critical for supporting HBV screening and optimization of treatment in HIV/HBV coinfected patients.

\section{Conflict of Interests}

The authors declare that there is no conflict of interests regarding the publication of this paper.

\section{Acknowledgments}

In memory of Dr. Michael Chirara, the authors wish to acknowledge his contribution to this study. The study had approval from the University of Zimbabwe College of Health Sciences, Department of Medical Microbiology.

\section{References}

[1] C. J. Hoffmann and C. L. Thio, "Clinical implications of HIV and hepatitis B co-infection in Asia and Africa," The Lancet Infectious Diseases, vol. 7, no. 6, pp. 402-409, 2007.

[2] World Health Organisation Fact sheet no. 204, July 2012, http:// www.who.int/mediacentre/factsheets/fs204/en/index.html.

[3] S. Tswana, C. Chetsanga, L. Nyström, S. Moyo, M. Nzara, and L. Chieza, "A sero-epidemiological cross-sectional study of hepatitis B virus in Zimbabwe," South African Medical Journal, vol. 86, no. 1, pp. 72-75, 1996.

[4] UNAIDS Global AIDS response progress report 2012, http:// www.unaids.org/en/dataanalysis/knowyourresponse/countryprogressreports/2012countries/ce_ZW_Narrative_Report.pdf.

[5] R. J. Burnett, G. Francois, M. C. Kew et al., "Hepatitis B virus and human immunodeficiency virus co-infection in sub-Saharan Africa: a call for further investigation," Liver International, vol. 25, no. 2, pp. 201-213, 2005.

[6] S. H. Mayaphi, T. M. Rossouw, D. P. Masemola, S. A. Olorunju, M. Jeffrey Mphahlele, and D. J. Martin, "HBV/HIV co-infection: the dynamics of HBV in South African patients with AIDS," South African Medical Journal, vol. 102, no. 3, pp. 157-162, 2012.

[7] A. Lukhwareni, R. J. Burnett, S. G. Selabe, M. O. Mzileni, and M. J. Mphahlele, "Increased detection of HBV DNA in HBsAgpositive and HBsAg-negative South African HIV/AIDS patients enrolling for highly active antiretroviral therapy at a tertiary hospital," Journal of Medical Virology, vol. 81, no. 3, pp. 406-412, 2009.

[8] C. P. Desmond, S. Gaudieri, I. R. James et al., "Viral adaptation to host immune responses occurs in chronic hepatitis B virus (HBV) infection, and adaptation is greatest in HBV e AntigenNegative Disease," Journal of Virology, vol. 86, no. 2, pp. 11811192, 2012.

[9] R. K. Sterling, "Hepatitis B Virus in the Setting of HIV Infection: A Clinical Challenge," Medical writers circle, 2003, http://www.hcvadvocate.org/hcsp/articles/Sterling-1.html.

[10] N. J. Bodsworth, D. A. Cooper, and B. Donovan, "The influence of human immunodeficiency virus type 1 infection on the development of the hepatitis B virus carrier state," The Journal of Infectious Diseases, vol. 163, no. 5, pp. 1138-1140, 1991.

[11] C. L. Thio, E. C. Seaberg, R. Skolasky Jr. et al., "HIV-1, hepatitis $\mathrm{B}$ virus, and risk of liver-related mortality in the Multicenter Cohort Study (MACS)," The Lancet, vol. 360, no. 9349, pp. 19211926, 2002.

[12] T. E. M. S. De Vriessluijs, J. G. P. Reijnders, B. E. Hansen et al., "Long-term therapy with tenofovir is effective for patients coinfected with human immunodeficiency virus and hepatitis $b$ virus," Gastroenterology, vol. 139, no. 6, pp. 1934-1941, 2010.

[13] C. Stephan, A. Berger, A. Carlebach et al., "Impact of tenofovircontaining antiretroviral therapy on chronic hepatitis B in a cohort co-infected with human immunodeficiency virus," Journal of Antimicrobial Chemotherapy, vol. 56, no. 6, pp. 10871093, 2005.

[14] M. B. Ristig, J. Crippin, J. A. Aberg et al., “Tenofovir disoproxil fumarate therapy for chronic hepatitis B in human immunodeficiency virus/hepatitis B virus-coinfected individuals for whom interferon- $\alpha$ and lamivudine therapy have failed," Journal of Infectious Diseases, vol. 186, no. 12, pp. 1844-1847, 2002. 
[15] C. L. Thio, "Hepatitis B and human immunodeficiency virus coinfection," Hepatology, vol. 49, no. 5, pp. S138-S145, 2009.

[16] A. Ramezani, M. Banifazl, M. Mohraz, M. Rasoolinejad, and A. Aghakhani, "Occult hepatitis B virus infection: a major concern in HIV-infected patients," Hepatitis Monthly, vol. 11, no. 1, pp. 710, 2011.

[17] V. C. Kantelhardt, A. Schwarz, U. Wend et al., "Re-evaluation of anti-HBc non-reactive serum samples from patients with persistent hepatitis B infection by immune precipitation with labelled HBV core antigen," Journal of Clinical Virology, vol. 46, no. 2, pp. 124-128, 2009.

[18] K. C. Kapembwa, J. D. Goldman, and S. Lakhi, "HIV, Hepatitis B, and Hepatitis C in Zambia," Journal of Global Infectious Diseases, vol. 3, no. 3, pp. 269-274, 2011.

[19] O. A. Ejele, C. A. Nwauche, and O. Erhabor, "The prevalence of hepatitis B surface antigenaemia in HIV positive patients in the Niger Delta Nigeria," Nigerian Journal of Medicine, vol. 13, no. 2, pp. 175-179, 2004.

[20] M. N. Mulders, V. Venard, M. Njayou et al., "Low genetic diversity despite hyperendemicity of hepatitis $\mathrm{B}$ virus genotype E throughout West Africa," The Journal of Infectious Diseases, vol. 190, no. 2, pp. 400-408, 2004.

[21] F. Rouet, M. L. Chaix, A. Inwoley et al., "HBV and HCV prevalence and viraemia in HIV-positive and HIV-negative pregnant women in Abidjan, Cote d'Ivoire: The ANRS 1236 study," Journal of Medical Virology, vol. 74, no. 1, pp. 34-40, 2004.

[22] J. J. Ott, G. A. Stevens, J. Groeger, and S. T. Wiersma, "Global epidemiology of hepatitis B virus infection: new estimates of age-specific HBsAg seroprevalence and endemicity," Vaccine, vol. 30, no. 12, pp. 2212-2219, 2012.

[23] GAVI ALLIANCE, "Investing in immunisation through the GAVI Alliance. The evidence base," http://www.gavi.org/library/ publications/the-evidence-base/investing-in-immunisationthrough-the-gavi-alliance--the-evidence-base/.

[24] E. A. Santos, M. V. Sucupira, J. Arabe, and S. A. Gomes, "Hepatitis B virus variants in an HIV-HBV co-infected patient at different periods of antiretroviral treatment with and without lamivudine," BMC Infectious Diseases, vol. 4, article 29, 2004.

[25] N. J. Shire, S. D. Rouster, N. Rajicic, and K. E. Sherman, "Occult hepatitis B in HIV-infected patients," Journal of Acquired Immune Deficiency Syndromes, vol. 36, no. 3, pp. 869-875, 2004.

[26] D. Neau, M. Winnock, T. Galperine et al., "Isolated antibodies against the core antigen of hepatitis B virus in HIV-infected patients," HIV Medicine, vol. 5, no. 3, pp. 171-173, 2004.

[27] M. K. Osborn, J. L. Guest, and D. Rimland, "Hepatitis B virus and HIV coinfection: relationship of different serological patterns to survival and liver disease," HIV Medicine, vol. 8, no. 5, pp. 271-279, 2007.

[28] P. Kallestrup, R. Zinyama, E. Gomo et al., "Low prevalence of hepatitis $\mathrm{C}$ virus antibodies in HIV-endemic area of Zimbabwe support sexual transmission as the major route of HIV transmission in Africa," AIDS, vol. 17, no. 9, pp. 1400-1402, 2003.

[29] B. C. Gärtner, W. Jung, C. Welsch et al., "Permanent loss of anti-HBc after reactivation of hepatitis $B$ virus infection in an anti-HBs and anti-HBc-positive patient after allogeneic stem cell transplantation," Journal of Clinical Virology, vol. 38, no. 2, pp. 146-148, 2007.

[30] S. Awerkiew, M. Däumer, M. Reiser et al., "Reactivation of an occult hepatitis B virus escape mutant in an anti-HBs positive, anti-HBc negative lymphoma patient," Journal of Clinical Virology, vol. 38, no. 1, pp. 83-86, 2007.
[31] V. Avettand-Fenoel, D. Thabut, C. Katlama, T. Poynard, and V. Thibault, "Immune suppression as the etiology of failure to detect anti-HBc antibodies in patients with chronic hepatitis B virus infection," Journal of Clinical Microbiology, vol. 44, no. 6, pp. 2250-2253, 2006. 

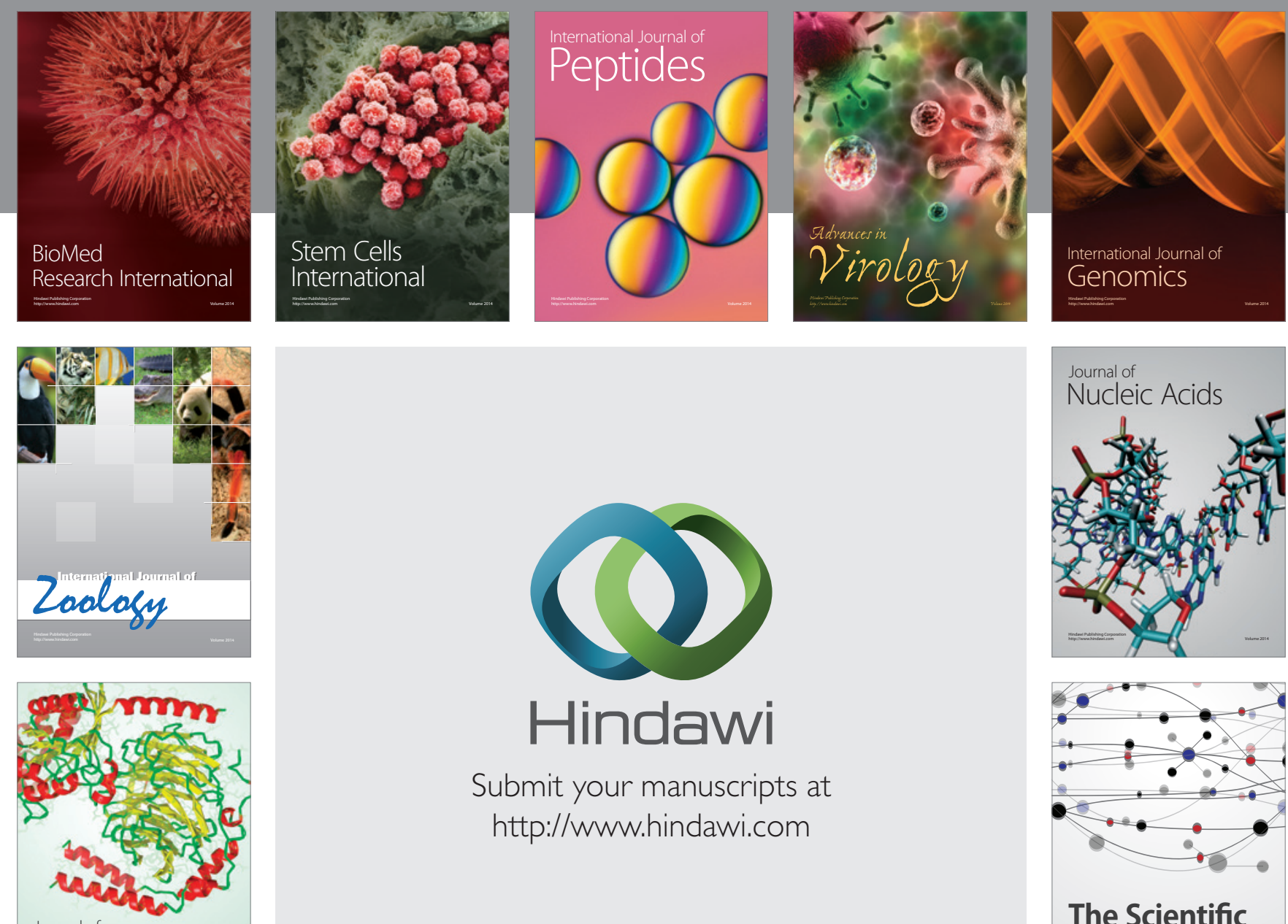

Submit your manuscripts at

http://www.hindawi.com

Journal of
Signal Transduction
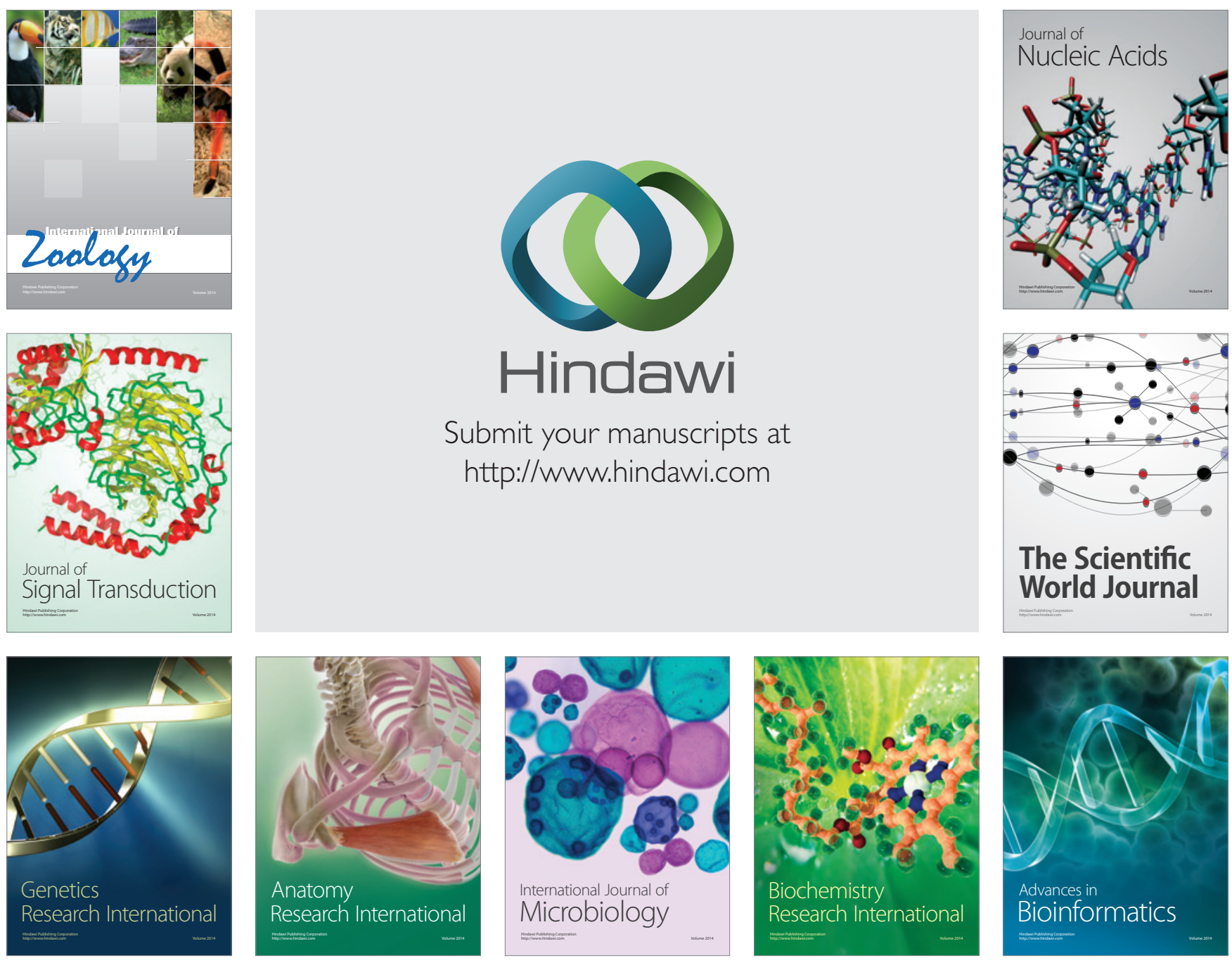

The Scientific World Journal
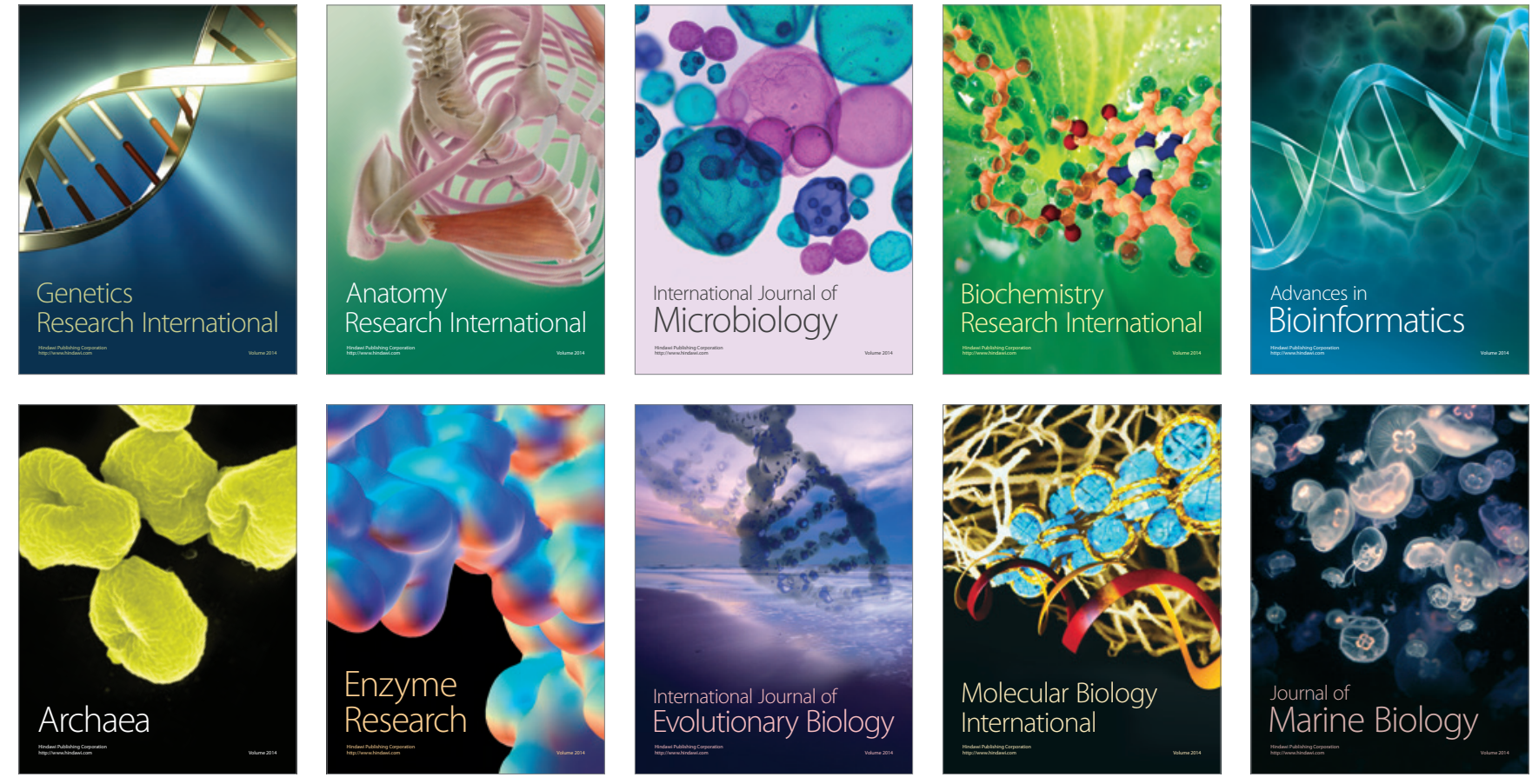